\title{
What does the COVID-19 pandemic mean for HIV, tuberculosis, and malaria control?
}

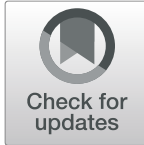

Floriano Amimo ${ }^{1,2^{*}}$ (D), Ben Lambert ${ }^{3}$ and Anthony Magit ${ }^{4}$

\begin{abstract}
Despite its current relatively low global share of cases and deaths in Africa compared to other regions, coronavirus disease 2019 (COVID-19) has the potential to trigger other larger crises in the region. This is due to the vulnerability of health and economic systems, coupled with the high burden of human immunodeficiency virus (HIV), tuberculosis (TB), and malaria. Here we examine the potential implications of COVID-19 on the control of these major epidemic diseases in Africa. We use current evidence on disease burden of HIV, TB, and malaria, and epidemic dynamics of COVID-19 in Africa, retrieved from the literature. Our analysis shows that the current measures to control COVID-19 neglect important and complex context-specific epidemiological, social, and economic realities in Africa. There is a similarity of clinical features of TB and malaria, with those used to track COVID-19 cases. This coupled with institutional mistrust and misinformation might result in many patients with clinical features similar to those of COVID-19 being hesitant to voluntarily seek care in a formal health facility. Furthermore, most people in productive age in Africa work in the informal sector, and most of those in the formal sector are underemployed. With the current measures to control COVID-19, these populations might face unprecedented difficulties to access essential services, mainly due to reduced ability of patients to support direct and indirect medical costs, and unavailability of transportation means to reach health facilities. Therefore, if not accompanied with appropriate economic and epidemiological considerations, we anticipate that these measures might result in unprecedented difficulties among vulnerable segments of society to access essential services, including antiretroviral and prophylactic drugs among people living with HIV and Acquired Immune Deficiency Syndrome, anti-tuberculosis drugs, and curative and preventive treatments for malaria among pregnant women and children. This might increase the propensity of patients taking substandard doses and/or medicines, which has the potential to compromise drug efficacy, and worsen health inequalities in the region. COVID-19 responses at country level should include measures to protect vulnerable and under-served segments of society.
\end{abstract}

Keywords: COVID-19, HIV, Tuberculosis, Malaria, Health systems, Africa

\section{Introduction}

As health professionals, communities, governments, and global institutions work closely to halt the spread of coronavirus disease 2019 (COVID-19) and mitigate its societal impact, the number of cases and deaths continues to rise globally. To date, the disease - first reported in Wuhan, China, on 8 December 2019 and declared a

\footnotetext{
* Correspondence: florianoamimo@gmail.com

'Department of Global Health Policy, Graduate School of Medicine, The University of Tokyo, Tokyo, Japan

${ }^{2}$ Faculty of Medicine, Eduardo Mondlane University, Maputo, Mozambique Full list of author information is available at the end of the article
}

pandemic by the World Health Organization (WHO) on 11 March 2020-has been reported in about 185 countries and territories [1]. Of these, 45 are in the WHO African region where human immunodeficiency virus (HIV), tuberculosis (TB), and malaria are endemic. With about 8767 confirmed cases and 413 attributable deaths as of 13 April 2020, the global share of COVID-19 cases and deaths in Africa remains below that of other WHO regions $[1,2]$.

To date, most analyses have explored the potential effects of the pandemic on the capability of health systems across the continent to deliver essential services,

(c) The Author(s). 2020 Open Access This article is licensed under a Creative Commons Attribution 4.0 International License, which permits use, sharing, adaptation, distribution and reproduction in any medium or format, as long as you give appropriate credit to the original author(s) and the source, provide a link to the Creative Commons licence, and indicate if changes were made. The images or other third party material in this article are included in the article's Creative Commons licence, unless indicated otherwise in a credit line to the material. If material is not included in the article's Creative Commons licence and your intended use is not permitted by statutory regulation or exceeds the permitted use, you will need to obtain permission directly from the copyright holder. To view a copy of this licence, visit http://creativecommons.org/licenses/by/4.0/. 
focusing on the response to COVID-19 [3-5]. However, the tremendous risk of COVID-19 on the continent goes beyond shortages of resources and infrastructure needed to directly manage the pandemic. In this study, we focus on the effect of the pandemic on the capacity of patients to use essential health services. We first describe the current dynamics of the pandemic across the WHO African region, using laboratory-confirmed cases and attributable deaths counts from the Center for Systems Science and Engineering at Johns Hopkins University [2]. Subsequently, we examine the potential implications of COVID-19 on other epidemic diseases so far responsible for the largest mortality, morbidity, and disability share on the continent. We use the current evidence on the disease burden of HIV, TB, and malaria, and the epidemic patterns of COVID-19 in the WHO African region retrieved from the literature to support our analysis. The data used in this analysis are drawn from the references provided.

\section{Analysis and discussion}

In the WHO African region, the first COVID-19 case was reported in Algeria on 25 February 2020. Among African Union member states, this was the second case, after the disease was first reported in Egypt on 14 February 2020. Since then, the disease has spread exponentially across the continent. Currently, the region representing approximately $13.7 \%$ of the global population $(1,019,922,000 / 7,430,261,000)$ [6], accounts for about $0.5 \%(8767 / 1,776,157)$ of the global share of COVID-19 cases and about $0.4 \%$ of the global share of attributable deaths $(413 / 108,804)[1,2]$ as of 13 April 2020. South Africa has emerged as the epicenter of the disease in the region, accounting for the largest share of cases reported to date [1]. There is a notable crosscountry variability in case fatality rate (CFR) in the WHO Africa region [2]. Even so, current data suggest that most countries in the region have death rates that are below the global time delay adjusted CFR estimate of 5.7\% (95\% confidence interval: 5.5-5.9\%) [7].

The relatively low global share of cases and deaths in Africa might be explained in part by the population age structure. This is because clinical severity of COVID-19 increases with age [8], and the populations across the continent are largely young, with a median age of approximately 18.7 years, compared to the global median age of approximately 30.2 years [6]. However, limited availability of detailed patient-level data, underascertainment of mild cases, and mis-assignment of causes of death pose important challenges for the accurate estimation of CFR [9]. This means that, in addition to population age structure, the current CFR in the region might also be a reflection of the fact that patients diagnosed with COVID-19 in most African countries are usually those with symptoms as asymptomatic patients might not be easily accessible to the health system. Therefore, a significant portion of COVID-19 cases and attributable deaths across the continent is probably not being accounted for in official statistics. Lack of testing and contact tracing capability is a significant contributor as well.

Despite the relatively low cases counts and death rates in most African countries, COVID-19 poses an unprecedented public health risk on the continent. This is, among other factors [3-5], because of the high burden of other endemic diseases. Globally, the regions with the largest share of people living with HIV/AIDS (PLWHA) are Eastern and Southern Africa, with 20.6 million (18.2-23.2 million), and Western and Central Africa, with 5.0 million (4.0-6.3 million) [10]. Among PLWHA, TB is the leading cause of death. In contrast to COVID19 , CFR of TB is $15.7 \%$ in the general population, $32.6 \%$ among PLWHA, and $41.0 \%$ among patients with Rifampicin-resistant or multidrug-resistant TB [11]. Clinically, TB presents with fever, cough, and dyspnea, among other symptoms. Despite the differences in the duration of incubation and others, these three symptoms are also the clinical features observed in most patients with COVID-19, with prevalence of $88.7 \%$ (84.5-92.9\%), $57.6 \%(40.8-74.4 \%)$, and $45.6 \%(10.9-80.4 \%)$, respectively [12]. Additionally, the WHO African region accounts for $93 \%$ of total malaria cases and $94 \%$ of total malaria deaths [13]. There have been important reductions in malaria deaths in the past two decades. To ensure continued reductions in malaria death rates, cases need to be correctly diagnosed and promptly treated. The main diagnostic characteristic of malaria is fever $[14,15]$. Therefore, the similarity of symptoms poses important challenges to the current measures to control, not only COVID-19, but TB and malaria as well.

Furthermore, the current measures to control COVID19 include quarantine of suspected cases, isolation of infected patients, contact tracing, and among other strategies $[16,17]$. These might not have good acceptability in some communities $[18,19]$. Therefore, many patients with clinical features similar to those of severe acute respiratory syndrome coronavirus 2 (SARS-CoV-2) infection, which might be COVID-19, and/or any other disease with similar symptomatology, might be hesitant to voluntarily seek testing and treatment in a formal health facility. Additionally, in most cases SARS-CoV-2 infection presents itself with mild symptoms. This coupled with fear of high scrutiny that might be associated with a COVID-19 diagnosis may also lead to individuals not seeking care and therefore facilitate the spread of the pandemic. Even though contact tracing is vital to halt transmission, some patients might have privacy concerns [20]. This was observed during the Ebola 
outbreak in Central and West Africa, in part due to institutional mistrust and misinformation [21]. This might result in an increased household transmission of COVID-19 as infected family members will remain in contact with uninfected patients without any protective measure. Transmission of COVID-19 occurs even among asymptomatic and paucisymptomatic patients. These factors might result in an increased risk of complications and mortality among vulnerable populations because they might delay or avoid seeking care in a formal health facility. For pregnant women with untreated malaria, the complications-usually underestimated-are twofold, comprising maternal and child adverse outcomes [22].

Reduced ability of patients to access health services among under-served and vulnerable segments of society is another critical challenge. To curb the spread of the pandemic, governments are implementing measures, which in addition to limitations to travel and business, also include closure of schools and universities, as well as recommendations for people to stay home. However, most people in productive age in Africa work in the informal sector, and most of those in the formal sector are underemployed $[23,24]$. Therefore, if these measures are enforced without appropriate economic and epidemiological considerations, millions of vulnerable populations across the continent might face unprecedented difficulties to access health services due to limited disposable income to support transportation expenses, as well as other direct and indirect medical costs. Among others, these populations include: (1) PLWHA who need to access health facilities regularly to retrieve antiretroviral and prophylactic drugs; (2) patients under treatment for TB who need to go to health facilities regularly to access antituberculosis drugs; (3) approximately 11 million pregnant women exposed to Plasmodium falciparum infection annually who need intermittent preventive treatment for malaria prevention as part of antenatal care services; and (4) approximately 24 million children infected with Plasmodium falciparum annually who need correct diagnosis and prompt treatment of malaria [13]. This is compounded by the fact that nearly $287,282,013$ (29.0\%) people and 64,495,526 (28.2\%) women of reproductive age need to travel more than $2 \mathrm{~h}$ to reach the nearest health facility [25]. Additionally, COVID-19 control measures in some countries include limitation of number of passengers in public transportation. This might worsen the availability of transportation means to reach health facilities.

\section{Conclusions}

The current measures to control the pandemic, as they are being enforced across the continent, neglect important and complex context-specific realities in Africa. We anticipate an unprecedented reduction in the capacity of patients to use health services. Limited access to essential medicines is known to create the conditions for patients to use substandard drugs and/or doses. This, in addition to reducing patient outcomes by increasing morbi-mortality due to HIV/AIDS, TB, and malaria, might contribute to the emergence and spread of drugresistant pathogens. Moreover, reduced access to effective antituberculosis treatment might increase infectiousness of TB patients. This has the potential to trigger other larger crises in the region and could worsen health inequalities and result in reversal of global health gains in key indicators. Therefore, COVID-19 responses at country level should be tailored to local social, epidemiological, and economic profiles. These should include measures to protect under-served and vulnerable populations, in particular PLWHA, patients with comorbidities and other risk factors, communities living in malaria endemic settings, pregnant women, people under treatment for tuberculosis, and other relevant segments of society. These populations need protection not only from the pandemic, but also from the consequences of its control measures.

\section{Abbreviations \\ AIDS: Acquired Immune Deficiency Syndrome; CFR: Case fatality rate; COVID- 19: Coronavirus disease 2019; HIV: Human immunodeficiency virus; \\ PLWHA: People living with HIV/AIDS; SARS-CoV-2: Severe acute respiratory syndrome coronavirus 2; TB: Tuberculosis; WHO: World Health Organization}

\section{Acknowledgements}

Not applicable

\section{Authors' contributions}

FA conceived of and designed the research, reviewed the literature, prepared the data, drafted the manuscript, and contributed to the revision of the final manuscript. BL and AM reviewed the manuscript, supported the interpretation, and contributed to the revision of the final manuscript. All authors read and approved the final manuscript.

Funding

Ministry of Education, Culture, Sports, Science, and Technology of Japan.

Availability of data and materials

The data used in this analysis are drawn from the references provided.

Ethics approval and consent to participate

Ethical approval is not necessary because this research did not collect identifiable human material and data.

Consent for publication

Not applicable

Competing interests

The authors declare that they have no competing interests.

Author details

'Department of Global Health Policy, Graduate School of Medicine, The University of Tokyo, Tokyo, Japan. 'Faculty of Medicine, Eduardo Mondlane University, Maputo, Mozambique. ${ }^{3} \mathrm{MRC}$ Centre for Global Infectious Disease Analysis, School of Public Health, Imperial College London, London, UK. ${ }^{4}$ Human Research Protection Program, University of California San Diego School of Medicine, San Diego, CA, USA. 
Received: 17 April 2020 Accepted: 30 April 2020

Published online: 13 May 2020

\section{References}

1. World Health Organization. Coronavirus disease 2019 (COVID-19): situation reports. World Health Organization; 2020. https:/www.who.int/ emergencies/diseases/novel-coronavirus-2019/situation-reports.

2. Dong $\mathrm{E}, \mathrm{Du} \mathrm{H}$, Gardner L. An interactive web-based dashboard to track COVID-19 in real time. Lancet Infect Dis. 2020 May:20(5):533-44.

3. Paintsil E. COVID-19 threatens health systems in sub-Saharan Africa: the eye of the crocodile. J Clin Invest. 2020.

4. Gilbert M, Pullano G, Pinotti F, Valdano E, Poletto C, Boëlle P-Y, et al. Preparedness and vulnerability of African countries against importations of COVID-19: a modelling study. Lancet. 2020;395(10227):871-7.

5. Nuwagira E, Muzoora C. Is Sub-Saharan Africa prepared for COVID-19? Tropical Medicine and Health. 2020;48(1):1-3.

6. World Health Organization. Global health observatory data repository. Geneva. Switzerland: World Health Organization; 2018. p. 2018.

7. Baud D, Qi X, Nielsen-Saines K, Musso D, Pomar L, Favre G. Real estimates of mortality following COVID-19 infection. Lancet infect dis. 2020.

8. Verity R, Okell LC, Dorigatti I, Winskill P, Whittaker C, Imai N, et al. Estimates of the severity of coronavirus disease 2019: a model-based analysis. Lancet Infect Dis. 2020.

9. Wu JT, Leung K, Bushman M, Kishore N, Niehus R, de Salazar PM, et al. Estimating clinical severity of COVID-19 from the transmission dynamics in Wuhan, China. Nat Med. 2020:1-5.

10. Joint United Nations Programme on HIV and AIDS. Global HIV Statistics. Joint United Nations Programme on HIV and AIDS; 2019.

11. MacNeil A, Glaziou P, Sismanidis C, Maloney S, Floyd K. Global Epidemiology of tuberculosis and progress toward achieving global targets - 2017. MMWR Morb Mortal Wkly Rep. 2019;68(11):263-6.

12. Rodriguez-Morales AJ, Cardona-Ospina JA, Gutiérrez-Ocampo E, VillamizarPeña R, Holguin-Rivera Y, Escalera-Antezana JP, et al. Clinical, laboratory and imaging features of COVID-19: a systematic review and meta-analysis. Travel Med Infect Dis. 2020:101623.

13. World Health Organization. World malaria report 2019. World Health Organization; 2019.

14. Schumann RR. Malarial fever: hemozoin is involved but Toll-free. Natl Acad Sci USA. 2007;104(6):1743-4.

15. Maze MJ, Bassat Q, Feasey NA, Mandomando I, Musicha P, Crump JA. The epidemiology of febrile illness in sub-Saharan Africa: implications for diagnosis and management. Clin Microbiol Infect. 2018;24(8):808-14.

16. Hellewell J, Abbott S, Gimma A, Bosse NI, Jarvis Cl, Russell TW, et al. Feasibility of controlling COVID-19 outbreaks by isolation of cases and contacts. Lancet Glob Health. 2020;8(4):e488-e96.

17. Nussbaumer-Streit B, Mayr V, Dobrescu Al, Chapman A, Persad E, Klerings I, et al. Quarantine alone or in combination with other public health measures to control COVID-19: a rapid review. Cochrane Database of Systematic Reviews. 2020;4

18. Kpanake L, Leno J-P, Sorum PC, Mullet E. Acceptability of community quarantine in contexts of communicable disease epidemics: perspectives of literate lay people living in Conakry, Guinea. Epidemiol Infect. 2019;147:e248.

19. Desclaux A, Badji D, Ndione AG, Sow K. Accepted monitoring or endured quarantine? Ebola contacts' perceptions in Senegal. Soc sci med. 2017;178: 38-45.

20. Zastrow M. South Korea is reporting intimate details of COVID-19 cases: has it helped? Nature; 2020.

21. Vinck P, Pham PN, Bindu KK, Bedford J, Nilles EJ. Institutional trust and misinformation in the response to the 2018-19 Ebola outbreak in North Kivu, DR Congo: a population-based survey. Lancet Infect Dis. 2019;19(5): 529-36.

22. Amimo F, Moon TD, Magit A, Sacarlal J, Lambert B, Nomura S. Trends in comparative efficacy and safety of malaria control interventions for maternal and child health outcomes in Africa: a study protocol for a Bayesian network meta-regression exploring the effect of HIV and malaria endemicity spectrum. BMJ open. 2019:9(2):e024313.

23. Kingdon GG, Knight J. Unemployment in South Africa: the nature of the beast. World development. 2004;32(3):391-408.

24. Galdino KM, Kiggundu MN, Jones CD, Ro S. The informal economy in panAfrica: review of the literature, themes, questions, and directions for management research. Afr. J. Bus. Manage. 2018;4(3):225-58.
25. Ouma PO, Maina J, Thuranira PN, Macharia PM, Alegana VA, English M, et al. Access to emergency hospital care provided by the public sector in subSaharan Africa in 2015: a geocoded inventory and spatial analysis. Lancet Global Health. 2018:6(3):e342-e50.

\section{Publisher's Note}

Springer Nature remains neutral with regard to jurisdictional claims in published maps and institutional affiliations.

\section{Ready to submit your research? Choose BMC and benefit from:}

- fast, convenient online submission

- thorough peer review by experienced researchers in your field

- rapid publication on acceptance

- support for research data, including large and complex data types

- gold Open Access which fosters wider collaboration and increased citations

- maximum visibility for your research: over $100 \mathrm{M}$ website views per year

At BMC, research is always in progress.

Learn more biomedcentral.com/submissions 